\title{
Simulating transmission of ESKAPE pathogens plus $C$. difficile in relevant clinical scenarios
}

Katharina L. Weber, Danielle S. LeSassier, Anthony D. Kappell, Kathleen Q. Schulte, Nicole Westfall, Nicolette C. Albright, Gene D. Godbold, Veena Palsikar, Carlos A. Acevedo, Krista L. Ternus and F. Curtis Hewitt “(1)

\begin{abstract}
Background: The prevalence of healthcare-acquired infections (HAl) and rising levels of antimicrobial resistance places significant economic and public health burdens on modern healthcare systems. A group of highly drug resistant pathogens known as the ESKAPE pathogens, along with $C$. difficile, are the leading causes of HAls. Interactions between patients, healthcare workers, and environmental conditions impact disease transmission. Studying pathogen transfer under varying contact scenarios in a controlled manner is critical for understanding transmission and disinfectant strategies. In lieu of human subject research, this method has the potential to contribute to modeling the routes of pathogen transmission in healthcare settings.
\end{abstract}

Methods: To overcome these challenges, we have developed a method that utilizes a synthetic skin surrogate to model both direct (skin-to-skin) and indirect (skin-to fomite-to skin) pathogen transfer between infected patients and healthy healthcare workers. This surrogate material includes a background microbiome community simulating typical human skin flora to more accurately mimic the effects of natural flora during transmission events.

Results: We demonstrate the ability to modulate individual bacterial concentrations within this microbial community to mimic bacterial concentrations previously reported on the hands of human subjects. We also explore the effect of various decontamination approaches on pathogen transfer between human subjects, such as the use of handwashing or surface disinfectants. Using this method, we identify a potential outlier, S. aureus, that may persist and retain viability in specific transfer conditions better than the overall microbial community during decontamination events.

Conclusions: Our work describes the development of an in vitro method that uses a synthetic skin surrogate with a defined background microbiota to simulate skin-to-skin and skin-to fomite-to skin contact scenarios. These results illustrate the value of simulating a holistic microbial community for transfer studies by elucidating differences in different pathogen transmission rates and resistance to common decontamination practices. We believe this method will contribute to improvements in pathogen transmission modeling in healthcare settings and increase our ability to assess the risk associated with HAls, although additional research is required to establish the degree of correlation of pathogen transmission by skin or synthetic alternatives.

Keywords: Healthcare-acquired infections, Pathogen transmission, Epidemiology, Synthetic skin, ESKAPE pathogens, C. difficile, Decontamination

\footnotetext{
* Correspondence: chewitt@signaturescience.com

Signature Science, LLC, Austin, TX, USA

(c) The Author(s). 2020 Open Access This article is licensed under a Creative Commons Attribution 4.0 International License, which permits use, sharing, adaptation, distribution and reproduction in any medium or format, as long as you give appropriate credit to the original author(s) and the source, provide a link to the Creative Commons licence, and indicate if changes were made. The images or other third party material in this article are included in the article's Creative Commons licence, unless indicated otherwise in a credit line to the material. If material is not included in the article's Creative Commons licence and your intended use is not permitted by statutory regulation or exceeds the permitted use, you will need to obtain permission directly from the copyright holder. To view a copy of this licence, visit http://creativecommons.org/licenses/by/4.0/ The Creative Commons Public Domain Dedication waiver (http://creativecommons.org/publicdomain/zero/1.0/) applies to the data made available in this article, unless otherwise stated in a credit line to the data.
} 


\section{Background}

Healthcare-acquired infections (HAIs) and increasing levels of antimicrobial resistance, particularly among HAI-associated pathogens, represent a significant source of morbidity and mortality cost in the US healthcare system [1]. Understanding the dynamics of pathogen transmission and transfer between patients, healthcare workers, and surrounding environmental surfaces is critical to evaluate potential intervention methods, identify possible environmental HAI reservoirs or fomites, and to delineate pathogen-specific transmission behaviors [2-5]. Ethical restrictions on human subject research complicates experimental analysis of human-to-human pathogen transfer. Retrospective studies on HAI outbreaks do not provide experimentally changeable parameters. Thus, there is a need for in vitro methods to study these types of transmission scenarios.

The ESKAPE pathogens (Enterococcus faecium, Staphylococcus aureus, Klebsiella pneumoniae, Acinetobacter baumannii, Pseudomonas aeruginosa, and Enterobacter species) [6] are a group of Grampositive and Gram-negative bacteria characterized by drug-resistance [6, 7]. Taken together with Clostridioides difficile, which is often caused by antibioticinduced disruption of the native gut microbiota [8], these pathogens (here termed ESKAPE $+\mathrm{C}$ ) collectively are the leading cause of nosocomial infections $[6,7]$. These pathogens employ diverse mechanisms of drug resistance, such as drug inactivation, active site modification, efflux pumps, and biofilm formation, leading to multidrug-resistant (MDR) strains and a need for novel antibiotics $[6,7,9,10]$. As a result of their clinical impact, the Centers for Disease Control and Prevention (CDC), with the Food and Drug Administration (FDA), maintains the Antibiotic Resistance (AR) Isolate Bank which maintains and curates multiple, well-characterized strains of ESKAPE pathogens and isolate panels, a resource that was utilized for this effort [11].

Previous studies have investigated surface transfer of individual ESKAPE $+C$ pathogens, focusing on outcomes of possible transmission events. Arinder et al. utilized VITRO-SKIN to show transfer rates of $S$. aureus to and from various fomites, but the study did not include relevant background microbiota [12]. Dyer et al. investigated C. difficile transmission from hospital fomites by directly applying spores to the fomite surface, which may not be representative for most transmission scenarios [13]. These studies take diverse approaches to investigating microbial transfer, making comparison of findings and transmission rates challenging. A standardized approach that is broadly applicable to relevant HAI pathogens would be beneficial in modeling pathogen transmission in healthcare-like scenarios.

In the current study, an in vitro method to enable investigation of both direct (skin-to-skin) and indirect (skin-to fomite-to skin) transmission scenarios of ESKAPE $+\mathrm{C}$ pathogens is presented. This method utilizes a commercially available synthetic skin surrogate, VITRO $\mathrm{SKIN}^{\circ} \mathrm{N}-19$, to mimic human skin and allow more accurate assessment of bacteria transmission behavior under various direct and indirect scenarios. We describe the inclusion of a set of background organisms commonly found on human skin, recapitulating the native microbiota present during such transmission events. Further, washing approaches for both VITRO-SKIN and relevant porous and nonporous surfaces (i.e., stainless steel, nitrile, and cotton) are presented. Using this method, ESKAPE $+C$ pathogens were found to transfer at different rates and the inclusion of washing methods for indirect, but not direct, scenarios generally reduced the transfer burden. The described approach is highly customizable, allowing researchers to investigate a specific surface, disinfectant methods, or pathogen(s) as desired.

\section{Results}

\section{Simulating direct and indirect contact scenarios}

Bacterial transmission can occur through either "direct" skin-to-skin contact, such as between an infected patient and a healthcare worker, or an "indirect" skin-to fomite-to skin transfer. We constructed a workflow to mimic these contact scenarios in order to investigate direct and indirect ESKAPE $+\mathrm{C}$ pathogen transfer utilizing VITROSKIN, a synthetic skin material (Fig. 1). As pathogen transfer does not occur in isolation, a set of "background" bacteria were included to represent the native skin microbiota that could be present on human hands. Table 1 lists the ESKAPE $+\mathrm{C}$ and background organisms used for this work. To simulate direct contact, a primary VITRO-SKIN coupon (i.e., infected patient) was briefly touched to a secondary VITRO-SKIN coupon containing only background organisms (i.e., healthy healthcare worker with a healthy skin flora) with or without a simulated handwashing step (Fig. 1a). For indirect contact, the primary VITRO-SKIN coupon was touched to an intermediate fomite (i.e., cotton, nitrile glove, or stainless steel). The surface was either washed or not washed before contact with the secondary VITRO-SKIN coupon (Fig. 1b). In both scenarios, viable pathogens were then recovered from the secondary coupon and enumerated. 


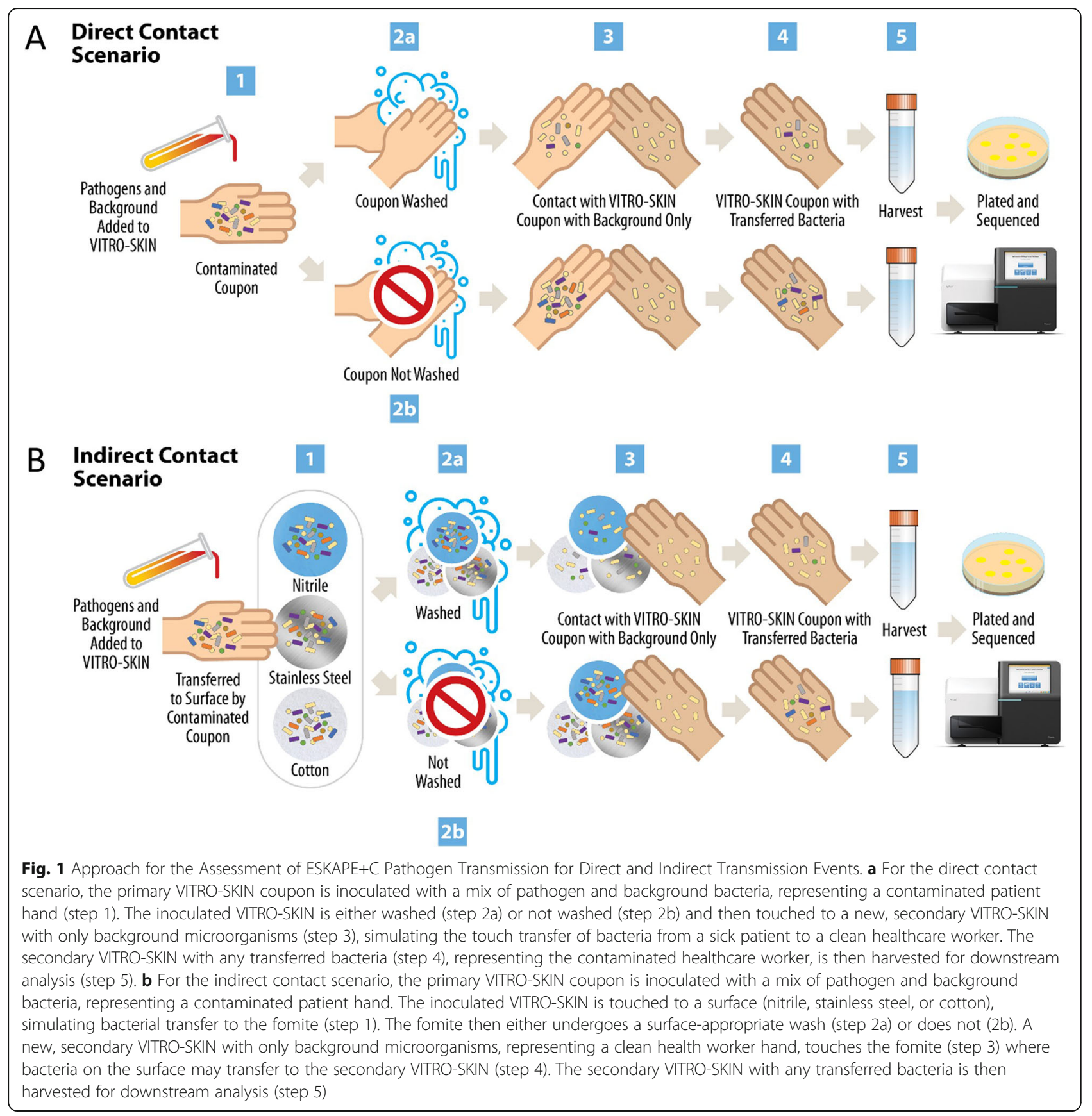

\section{Evaluation of bacterial loading on simulated skin}

Total bacterial loadings on the initial simulated skin coupon were quantified to ensure concordance with previously reported bacterial concentrations on the human hand. Published reports describing typical total microbial content on human hands in healthcare settings generally range between $3.9 \times 10^{4}$ and $4.6 \times 10^{6}$ colony forming units $(\mathrm{CFU}) / \mathrm{cm}^{2}[14]$. To better simulate a range of pathogen transmission scenarios, different amounts of pathogen were added to a consistent background microbiome community.
The pathogens were grouped into three mixes to better enable analysis by plating on selective media (Table 1). The "high" concentration samples contained approximately equivalent amounts of each microbial component $\left(10^{5} \mathrm{CFU} / \mathrm{cm}^{2}\right.$ or $10^{6} \mathrm{CFU}$ per 9 $\mathrm{cm}^{2}$ coupon). Pathogen amounts in the "low" concentration samples were 100-1000 fold less abundant in comparison. The amount of each pathogen, the background community, and the total amount of bacteria loaded onto the simulated skin coupon is shown in Fig. 2. 
Table 1 Bacteria used in this study

\begin{tabular}{ll}
\hline Background Microorganisms & Pathogenic Microorganisms \\
\hline Brevibacterium linens ATCC 9172 & $\begin{array}{l}\text { Acinetobacter baummannii } \\
\text { AR Bank 275 }\end{array}$ \\
Corynebacterium matruchotii & $\begin{array}{l}\text { Enterococcus faecium AR } \\
\text { Bank 579 } \\
\text { ATCC 14266 }\end{array}$ \\
Cutibacterium acnes ATCC 11827 & $\begin{array}{l}\text { Klebsilla pneumoniae AR } \\
\text { Bank 139 }\end{array}$ \\
Escherichia coli ATCC 9637 & Enterobacter aerogenes AR \\
Bactobacillus gasseri ATCC 33323 161 & Staphylococcus aureus AR \\
Mank 219 & Clostridioides difficile (endospores) \\
Micrococcus luteus ATCC 4698 43598 \\
Staphylococcus epidermidis & Enterobacter cloacae AR Bank 365 \\
ATCC 12228 & \\
Streptococcus pyogenes ATCC 49399 & Pseudomonas aeruginosa AR \\
& Bank 230 \\
\hline
\end{tabular}

\section{Pathogen transmission by direct contact}

The overall level of ESKAPE $+\mathrm{C}$ pathogen transfer from the primary VITRO-SKIN coupon to a secondary VITRO-SKIN coupon following direct contact was established by measuring the total CFU recovery from the secondary coupon. Figure 3 shows the total
CFU $\left(\log _{10}\right)$ of each pathogen following transfer for each bacterial mix (3A) or individual pathogen (3B). Each individual replicate is plotted $(n=3)$. The total inoculum on the initial coupon is indicated for comparison.

A. baumannii, E. aerogenes, E. faecium, K. pneumoniae, $P$. aeruginosa, and $S$. aureus had significantly greater direct transfer with smaller log differences at lower inoculum ranging from 0.213 to 1.70 compared to higher inoculum with log differences ranging from 1.67 to $2.79(p<0.034)$. C. difficile $(p=0.999)$ and $E$. cloacae $(p=0.536)$ had no significant differences in direct transfer rates between the high and low inoculum used in this study. While the high inoculum samples generally transferred a greater number of total CFU in comparison with the lower inoculum samples (with the novel exception for E. faecium), higher pathogen concentrations led to lower overall pathogen transfer rates from the primary to the secondary coupon.

\section{Pathogen transmission by indirect contact}

Similar to the direct transfer testing described above, total CFU counts were measured for each mix or individual ESKAPE $+\mathrm{C}$ pathogen recovered from the
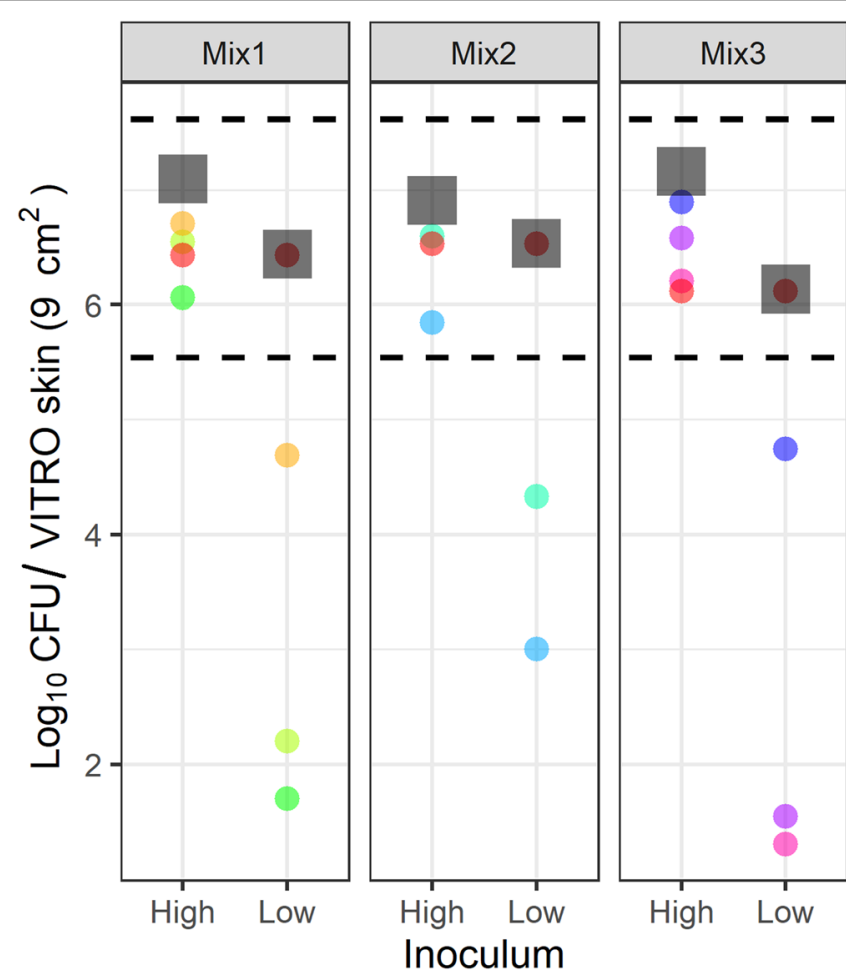

Total

- Background

- E. faecium

K. pneumoniae

- A. baumannii

S. aureus

- E. aerogenes

- C. difficile

- P. aeruginosa

E. cloacae

Fig. 2 Representative Bacterial Loadings on the Initial VITRO-SKIN Coupon. The ESKAPE+C pathogens were grouped into three separate mixes to facilitate culture-based screening at either high or low levels relative to a consistent background microbial community. Total loadings (black squares) for both the high and low inoculum levels fell within equivalent reported ranges (denoted by black dotted lines) of bacterial loads on the hands of healthcare workers (between $3.9 \times 10^{4}$ and $4.6 \times 10^{6} \mathrm{CFU} / 9 \mathrm{~cm}^{2}$ ) [14] 


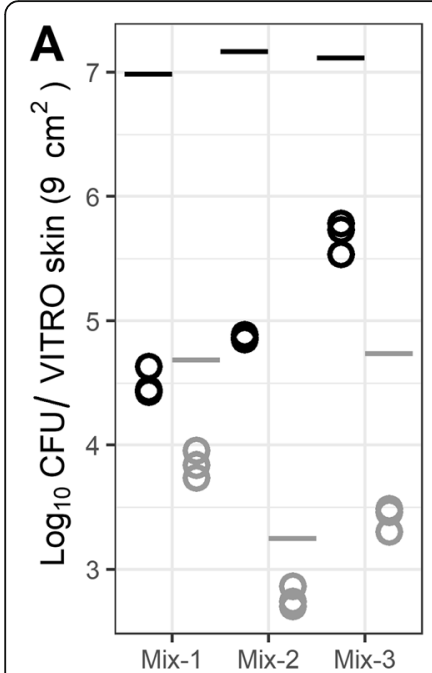

Mixture of Pathogens

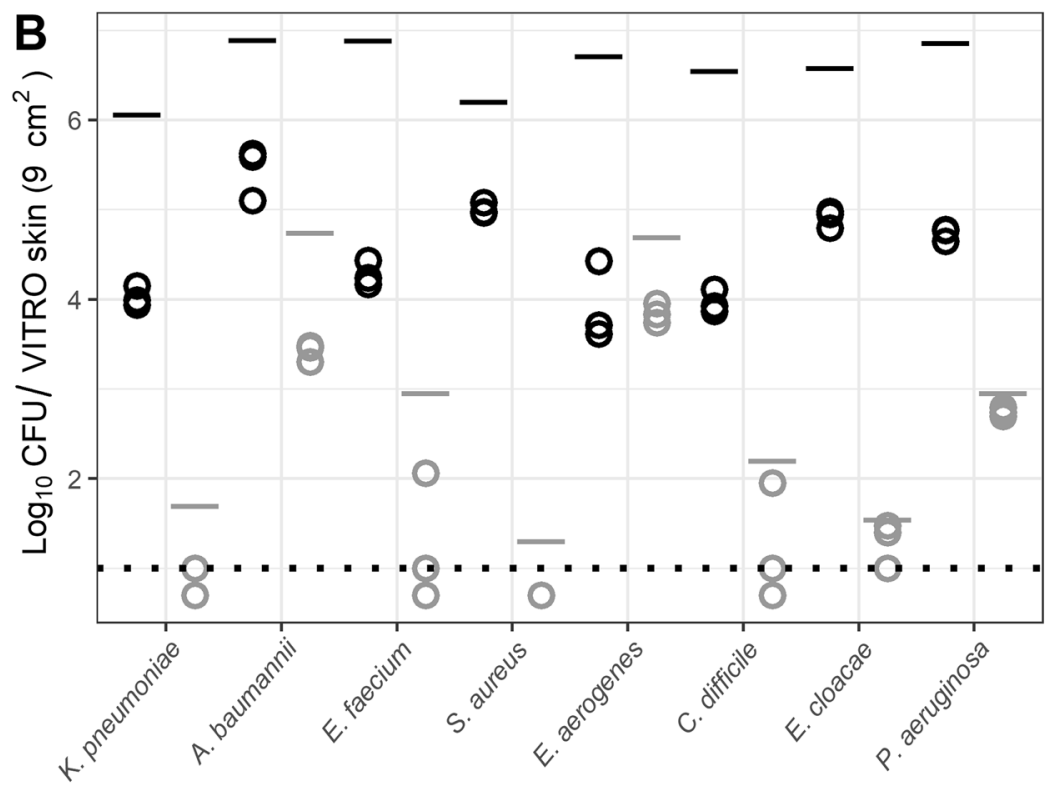

ESKAPE+C Organism

Fig. 3 Direct transfer of ESKAPE+C Organisms performed in mixture with high and low initial inoculum. a Total amount of pathogen recovered from secondary VITRO-SKIN coupon following direct transfer. The CFU transferred $\left(\log _{10}\right)$ within mixtures are represented by the sum of the CFU for each pathogen averaged across three replicates. $\mathbf{b}$ Total amount of individual ESKAPE+C organisms within the microbial community mixture recovered from the secondary VITRO-SKIN coupon following direct transfer. Each pathogen is represented by the mean total CFU for each pathogen across three replicates. Black or gray lines above each point indicate initial pathogen spike levels on the primary VITRO-SKIN coupon. Dotted-line represents the limit of detection. Points below the dotted line result from averaging between replicates when one replicate had zero CFU

secondary VITRO-SKIN coupon following indirect transfer. Indirect transfer involved transmission to a fomite (cotton, nitrile, or stainless steel) from the initial VITRO-SKIN coupon followed by transmission from the fomite to the secondary VITRO-SKIN surface. As with the direct transfer data, total CFUs were plotted for both high and low pathogen innocula (Fig. 4). Initial pathogen inoculum levels are indicated by lines for estimation of overall transfer rates across each fomite type.

Overall, indirect transmission led to significantly lower transmission rates than direct transfer (fourway ANOVA including the factor for type of transfer: $\left.\mathrm{F}_{(1,160)}=17.4684, p<0.001\right)$ with CFU counts generally one to three orders of magnitude for high concentration innocula. A three-way analysis of variance (ANOVA) was conducted on the influence of inoculum, organism, and fomite type on the change in log concentration during indirect transfer of different mixtures of pathogen from VITRO-SKIN to a fomite to a VITRO-SKIN. The main effects inoculum $\left(\mathrm{F}_{(1,96)}=1426.5, \quad p<0.001\right)$, organism $\quad\left(\mathrm{F}_{(7,96)}=39.4\right.$, $p<0.001)$, fomite $\left(\mathrm{F}_{(2,96)}=10.4, p<0.001\right)$, and the interaction term of inoculum and organism $\left(\mathrm{F}_{(7,96)}=\right.$
21.0, $p<0.001)$ were statistically significant. Post-hoc Tukey honest significant difference test indicated significant differences between indirect transfer with cotton fomite compared to nitrile gloves $(p=0.023)$ and stainless steel $(p<0.001)$, while there was no significant difference in transfer between stainless steel and nitrile gloves $(p<0.160)$. Similar to direct transfer of pathogens, there was no significant difference in log differences between high and low inoculum of $C$. difficile $(p=1.00)$ and E. cloacae $(p=0.536)$. The other pathogens, A. baumannii, E. aerogenes, E. faecium, $K$. pneumoniae, $P$. aeruginosa, and S. aureus had significantly lower differences in log CFU at lower inoculum, ranging from 0.43 to 1.60 , than higher inoculum, ranging from 1.76 to 4.6 , indicating greater relative abundance transfer $(p<0.005)$. The three-way interaction term of all main effects $\left(\mathrm{F}_{(14,96)}=0.203, p=\right.$ $0.999)$ and interaction terms including fomite with inoculum $\quad\left(\mathrm{F}_{(2,96)}=0.389, \quad p=0.679\right)$ or organism $\left(\mathrm{F}_{(14,96)}=0.888, p=0.574\right)$ were not statistically significant. S. aureus represented the exception in the indirect transfer data, transferring at a higher rate across all three surfaces than the other ESKAPE $+\mathrm{C}$ pathogens. 


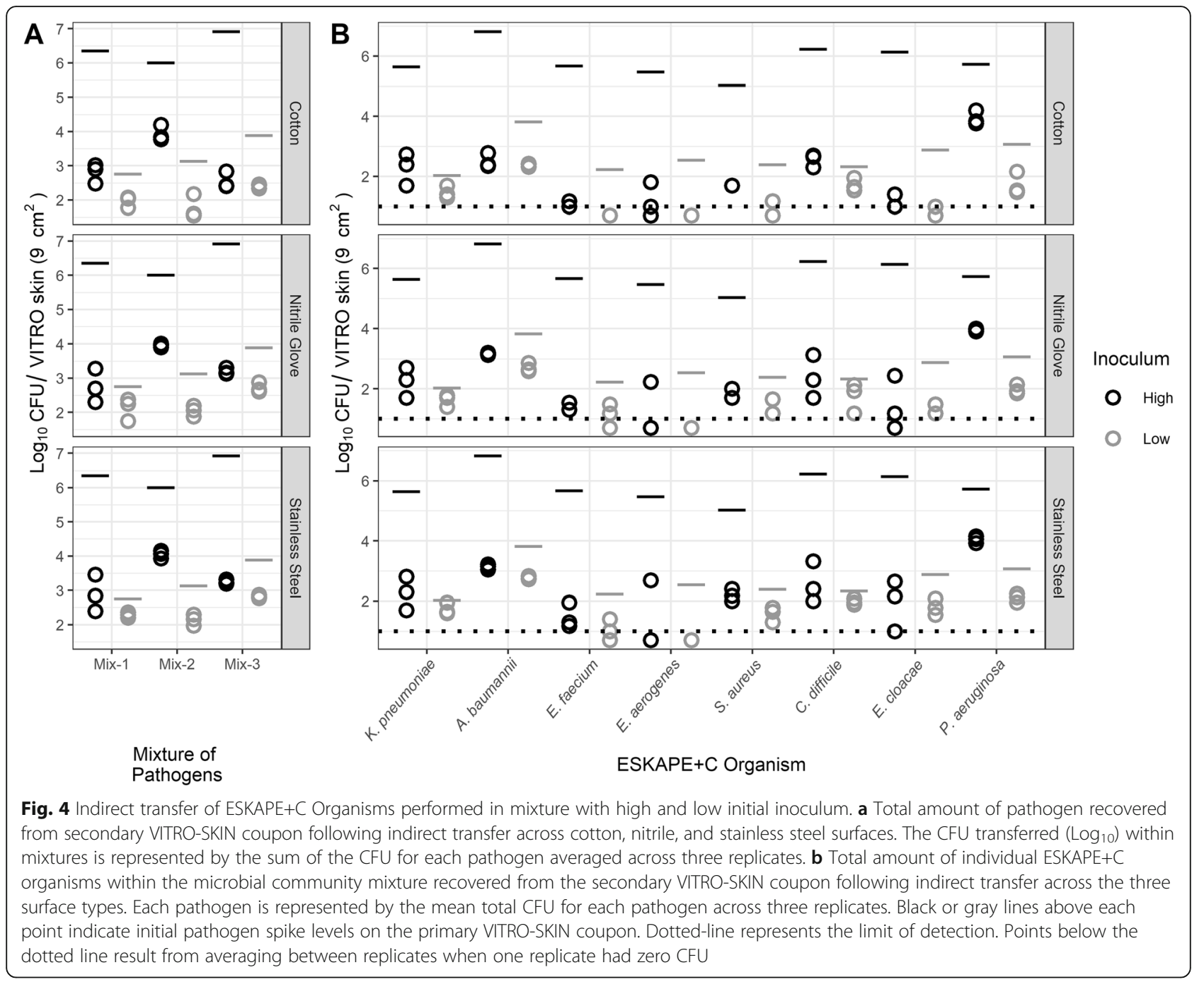

\section{Effect of simulated hand washing for direct contact scenarios}

The artificial skin method described herein provides opportunities to evaluate many facets of skin-to-skin pathogen transmission, including the effectiveness of hand washing or fomite decontamination methods. The effect of handwashing on direct transfer rates was simulated by manual scrubbing and immersion into a series of tubes containing phosphate buffered saline (PBS) to approximate rinsing. Overall, the effect of simulated hand washing was minimal, with washed samples generally demonstrating less than 10 -fold reduction in transferred pathogen compared to non-washed samples (Fig. 5). A three-way ANOVA was performed on the influence of inoculum, organism, and washing on the change in log change during direct transfer of mixtures of pathogen between VITRO-SKIN. The main effects inoculum $\quad\left(\mathrm{F}_{(1,64)}=410.5, \quad p<0.001\right), \quad$ organism $\left(\mathrm{F}_{(7,64)}=17.2, \quad p<0.001\right)$, and washing $\left(\mathrm{F}_{(1,64)}=17.5\right.$, $p<0.001)$, and the interaction terms with inoculum and organisms $\left(\mathrm{F}_{(7,64)}=10.57, p<0.001\right)$ or washing $\left(F_{(1,64)}=7.61, p=0.008\right)$ were statistically significant. Post-hoc Tukey honest significant difference test indicated a significantly greater log difference, less transfer, after washing compared to unwashed scenarios $(p<0.001)$. Post-hoc testing also indicated that washing the high inoculum samples significantly increased $\log$ difference and led to less transfer, compared to not washing $(p<0.001)$. There were no significant differences at low inoculum between washing and not washing $(p=0.748)$. The three-way interaction term of all main effects $\left(\mathrm{F}_{(7,64)}=0.821\right.$, $p=0.573)$ and the interaction term of washing and organisms $\left(\mathrm{F}_{(7,64)}=0.706, p=0.667\right)$ were not statistically significant. 


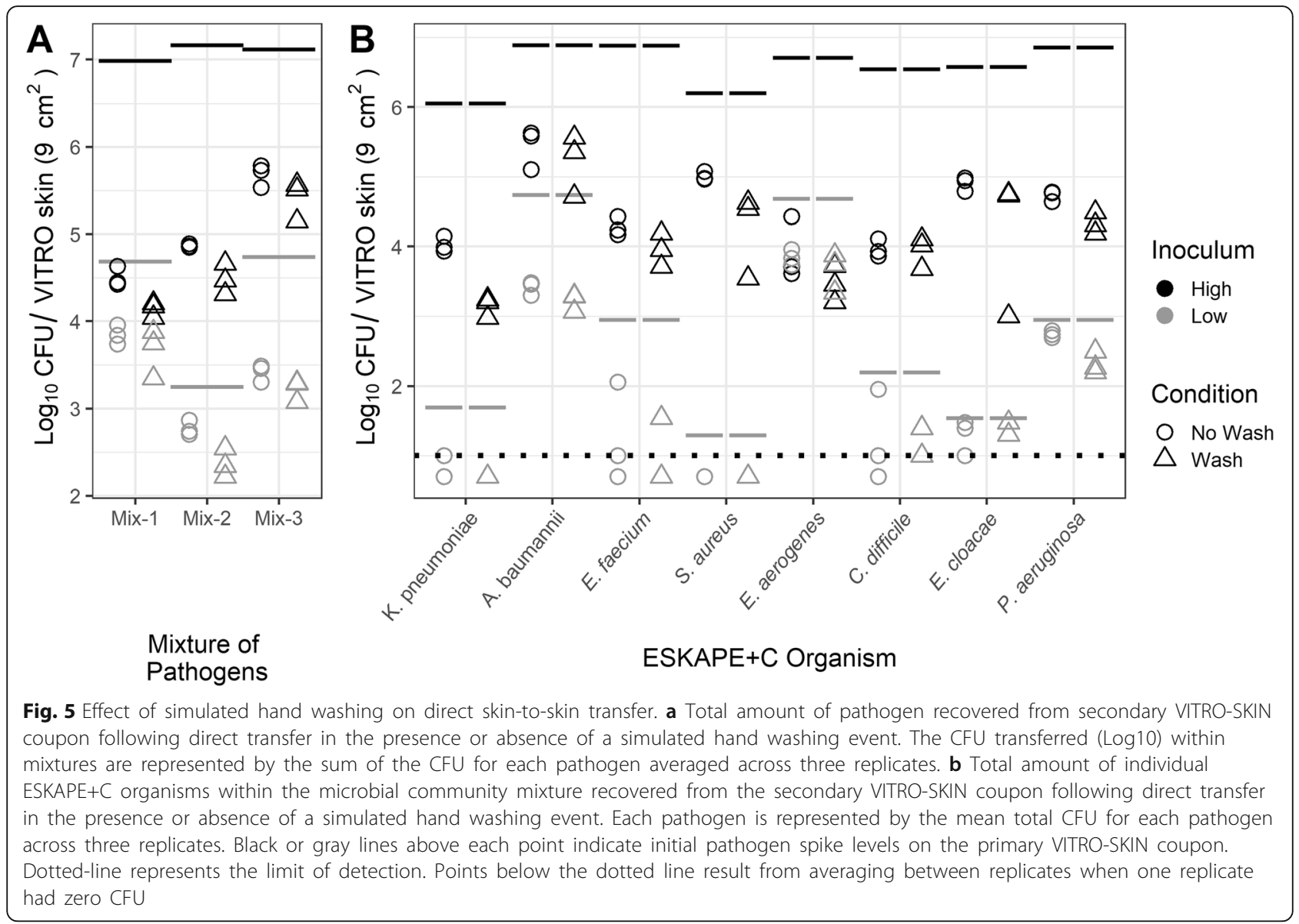

\section{Effect of simulated fomite decontamination for indirect contact scenarios}

The effect of fomite decontamination was also investigated (Fig. 6). Cotton samples were agitated in a soap solution to simulate laundering, while nitrile and stainless steel surfaces were swabbed with a disinfectant wipe. Cotton surfaces that were washed experienced $a \geq 6 \log$ CFU reduction in bacterial abundance compared to the unwashed samples for the high spike-in. A four-way ANOVA was performed on the influence of inoculum, organism, fomite type, and washing on the differences in $\log$ change during indirect transfer of mixtures of pathogens from VITRO-SKIN to fomite to VITRO-SKIN. The main effects inoculum $\left(\mathrm{F}_{(1,192)}=4915.73, p<0.001\right)$, organism $\quad\left(\mathrm{F}_{(7,192)}=192.65, \quad p<0.001\right), \quad$ fomite type $\left(\mathrm{F}_{(2,192)}=25.05, p<0.001\right)$, and washing $\left(\mathrm{F}_{(1,192)}=331.67\right.$, $p<0.001)$ were statistically significant. Additionally the interaction terms of inoculum and washing $\left(\mathrm{F}_{(7,192)}=\right.$ 88.67, $p<0.001)$, organism and washing $\left(\mathrm{F}_{(7,192)}=\right.$ $30.47, p<0.001)$, the three-way interaction term inoculum, organism, and washing $\left(\mathrm{F}_{(7,192)}=5.21, p<\right.$
0.001 ), and three-way interaction term organism, fomite type, and washing $\left(\mathrm{F}_{(14,192)}=2.04, p=0.017\right)$ were also statistically significant. At low inoculum, the pathogens A. baumannii, C. difficile, K. pneumoniae, $P$. aeruginosa, and $S$. aureus had less indirect transfer and greater log change after washing $(p<0.013)$. $C$. difficile, E. cloacae, E. aerogenes, and $P$. aeruginosa at high inoculum had less indirect transfer after washing $(p<0.04)$. The indirect transfer of E. faecium at high and low inoculum was not statistically significantly different $(p>0.984)$ after washing. Washing was most effective against the indirect transfer of $C$. difficile from all three surfaces examined $(p<0.001)$. Washing also significantly reduced the indirect transfer of $K$. pneumoniae on cotton surfaces $(p<0.001)$ and $P$. aeruginosa on stainless steel $(p<0.001)$. Similar to direct and indirect transfer without washing, the pathogens had significantly smaller log changes and higher overall relative transfer rates with low inoculum compared to high inoculum $(p<0.001)$ when washed, with the exception of $S$. aureus which demonstrated no statistically significant difference $(p=1.00)$. 


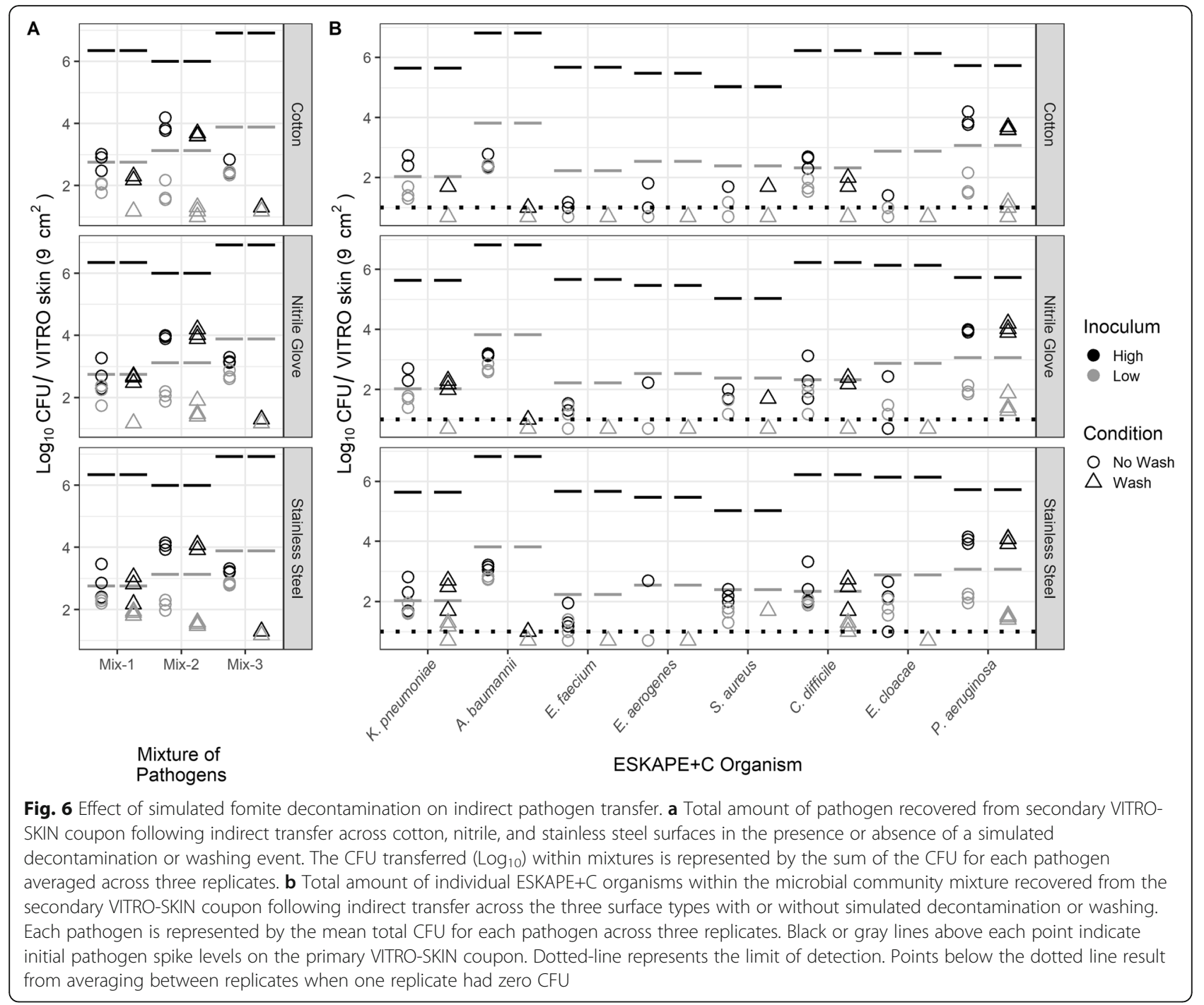

\section{Effectiveness of decontamination for the synthetic skin model}

To assess the overall effectiveness of the decontamination methods utilized in this study, the percent of total pathogen transferred from the initial to the secondary coupon was calculated. All raw data used for these calculations, including total bacterial loadings and total pathogen transferred for each replicate are included in Supplemental Table 1. Table S1 includes the calculated transfer rate for each pathogen and each replicate. These transfer rate values were averaged for each pathogen at each condition $(n=3)$ and plotted. Regression analysis was performed to compare percent transfer between washed and unwashed samples. In this case, a slope of $y=1$ would suggest no effect of washing on pathogen transfer, while a slope of $y=0$ would demonstrate complete pathogen removal or decontamination.
Figure 7a suggests that, in high inoculum samples, the success of decontamination was limited, especially on nitrile and stainless steel surfaces. Essentially equivalent amounts of pathogen were transferred across nitrile or stainless steel fomites regardless of the use of disinfectant wipes. Laundering the cotton surface or hand washing the direct contact samples decreased overall pathogen transmission rates approximately $60 \%$. However, the indirect transfer results were heavily skewed by a single pathogen, $S$. aureus. Removing the $S$. aureus outlier (Fig. 7b) reveals that the surface decontamination methods were reasonably effective for each of the other ESKAPE $+\mathrm{C}$ pathogens, reducing overall pathogen transmission by at least $80 \%$ in each case and nearly eliminating pathogen transmission across the laundered cotton fomite. These results align with previous findings regarding $S$. aureus and 

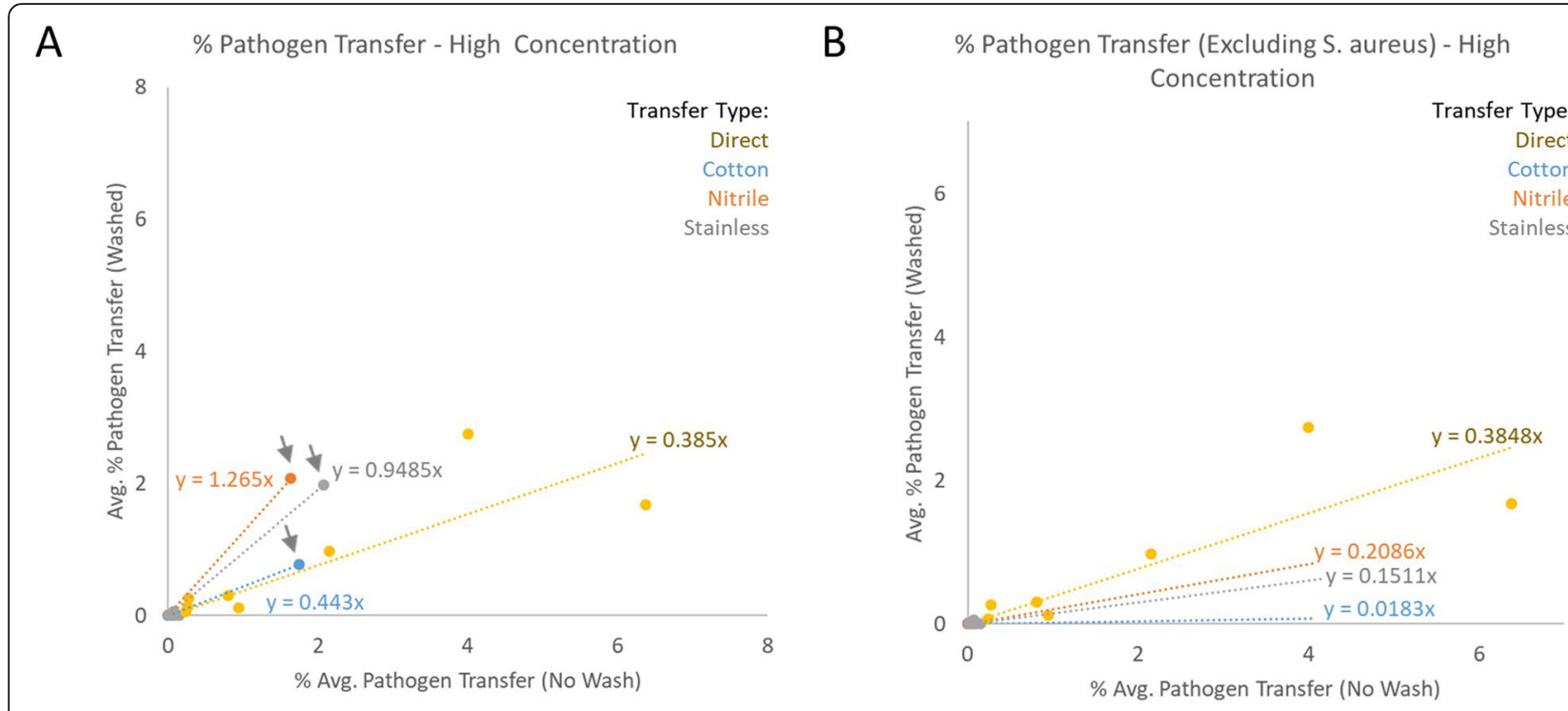

C

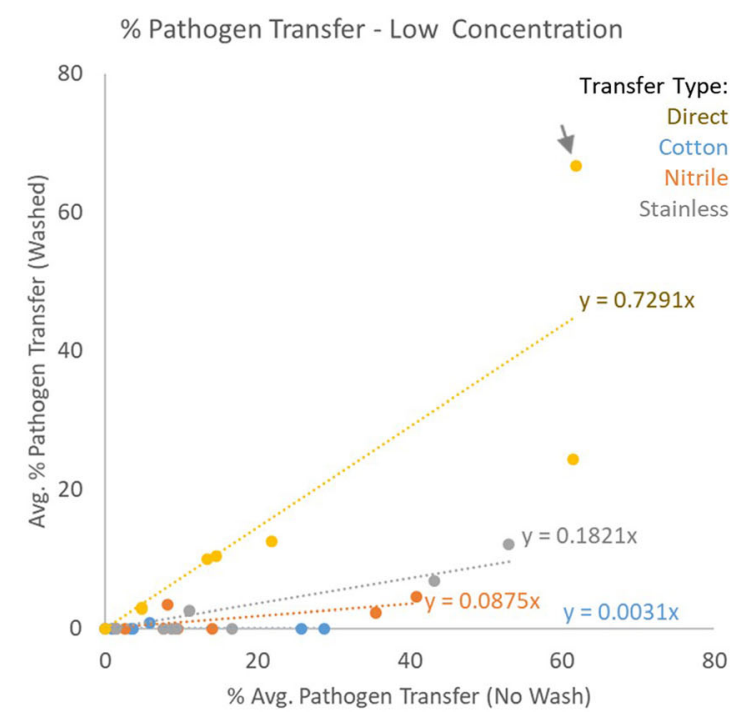

D

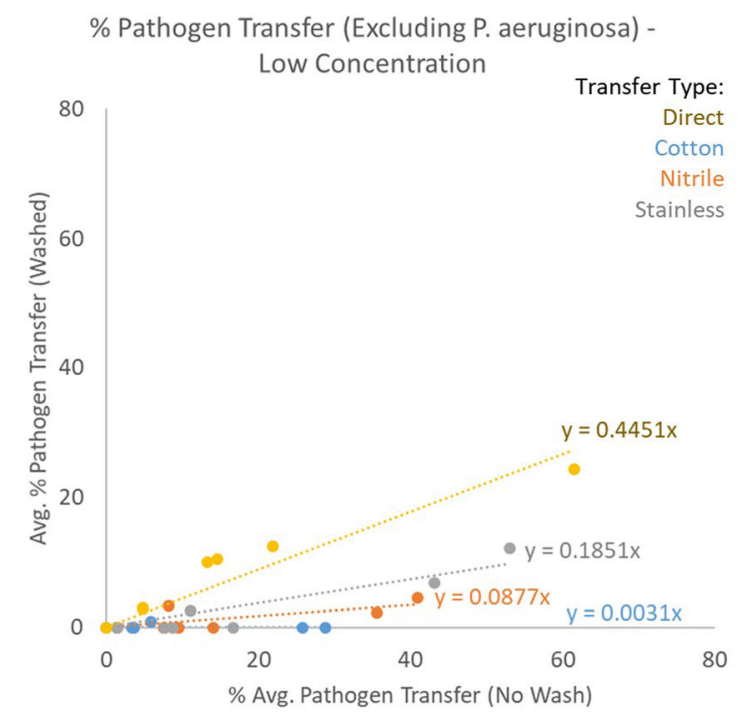

Fig. 7 Percent pathogen transfer from initial to secondary coupon at high and low pathogen concentration. Individual transfer scenarios (direct vs. indirect) are shown. The percent transferred when no wash or decontamination step was included is represented on the X-axis, with the percent transferred following a wash or decontamination step represented on the Y-axis. Values for individual pathogens were averaged $(n=3)$ prior to plotting. Linear regression lines were plotted with the slope of each line indicated. a Percent pathogen transfer at high initial pathogen concentration. S. aureus outlier results are indicated with gray arrows. B) Percent pathogen transfer at high initial pathogen concentration excluding S. aureus. b Percent pathogen transfer at high initial pathogen concentration excluding S. aureus. c Percent pathogen transfer at low initial pathogen concentration. P. aeruginosa outlier results are indicated with a gray arrow. D) Percent pathogen transfer at low initial pathogen concentration excluding $P$. aeruginosa

decontamination approaches on skin and related surface types $[12,15,16]$. The removal of $S$. aureus did not alter the overall direct transfer rates, suggesting the higher rate of $S$. aureus transfer in indirect scenarios arises from resistance to the fomite decontamination methods used.

Figure 7c demonstrates similar results for the low concentration pathogen samples. At low pathogen inoculum levels, fomite decontamination was largely effective, reducing pathogen transfer rates between 89 and 99\%. In contrast to the high concentration results, $S$. aureus was not an outlier at low inoculum levels. However, the transfer rate of $P$. aeruginosa was an outlier at the low inoculum level specifically for direct transfer, demonstrating nearly equivalent transfer rates in washed versus unwashed scenarios. Excluding $P$. aeruginosa from the 
analysis (Fig. 7d) decreased overall pathogen transfer rates for low inoculum direct transfer to levels approximating the high inoculum levels (compare yellow line between Fig. $7 \mathrm{a}$ and $\mathrm{d}$ ). P. aeruginosa transfer is commonly linked to hand hygiene and these results may be indicative of bacterial persistence on the hand following washing [17-19]. Exclusion of P. aeruginosa did not substantially affect the overall transfer rates observed in the indirect contact scenarios.

\section{Discussion}

The prevalence of healthcare-acquired infections (HAI) and rising levels of antimicrobial resistance places a significant economic burden on modern healthcare systems $[1,20]$. Epidemiological studies are commonly used to model or track pathogen transmission within the healthcare environment [21], but these studies are often limited by the amount of available data. Relevant synthetic systems, such as the one we describe, are critical to model and understand the transmission of pathogens in clinical settings because they do not require the involvement of human subjects. Such systems permit the generation of precise, quantitative data regarding pathogen transmission rates without risking the health of human subjects. The degree to which synthetic alternatives mimic the properties of human skin remains an open question worthy of further research.

The use of surrogate skin to understand pathogen transfer is not new, but such approaches may not be broadly relevant to the clinical setting due to the contrived nature of the sample [12, 22]. By producing and evaluating a method that incorporates a background microbial flora in addition to specific pathogens of interest, we have provided an additional tool in the arsenal of epidemiologists to study pathogen transmission within the healthcare setting in a way that could potentially be used to mimic the biology of the human hand. Additional work is required to establish the degree to which the VITRO-SKIN substrate mimics the human hand. While our method incorporates a background commensal skin microbial community to better model that of a human hand, adhesion of this community to the artificial surface may be different than adhesion to human skin. The properties and pressures of microbial growth on human skin over time likely cannot be fully recapitulated by the artificial surface. Future studies are needed to establish whether the artificial surface can support sustained microbial growth. If so, it may be possible to more accurately model the sudden introduction of pathogen (e.g., C. difficile) onto a hand with an established skin microbiome community.
By incorporating each of the ESKAPE $+\mathrm{C}$ pathogens into this testing, it was possible to compare relative transfer rates in both direct and indirect scenarios. $S$. aureus demonstrated a consistently higher transfer rate in the indirect contact scenarios, including persistence during decontamination or washing. It is unclear if this finding arises from surface properties of S. aureus that promote transfer or more robust fitness in comparison to the other pathogens used in the study resulting in greater viability during culture [23, 24]. E. faecium transferred at a higher rate in the low inoculum samples, with the total transferred CFU values nearly identical in direct contact scenarios despite the different input amounts (Fig. 4). Additional study is necessary to determine whether these findings are related to the biology of E. faecium or represent an artifact of the transfer and recovery method used in this study.

Several patterns emerged when evaluating pathogen transfer and the relative effectiveness of decontamination across transfer scenarios. As expected based on previous studies, $S$. aureus proved resistant to simulated decontamination on fomite surfaces, especially when present at high initial concentrations on nitrile and cotton (Fig. 6b and Fig. 7) [12, 15, 16]. P. aeruginosa persisted in a robust manner following washing or decontamination across direct and indirect transfer (Fig. 6b). This pattern emerged in a particularly clear fashion when comparing transfer rates of all pathogens for direct transfer at low concentration where $P$. aeruginosa appeared as an outlier in the overall trend of decontamination rates (Fig. 7c and d). It is not clear whether these results reflect underlying biological characteristics of these specific pathogens or could be due to artifacts arising from the specific decontamination procedures or artificial skin system used herein. Previous studies suggest that the properties of VITRO-SKIN may not perfectly align with those of human skin as it relates to the transfer of viruses [22]. It remains to be determined if the patterns observed herein are based on the intrinsic cellular properties of the pathogens and are not due to artifacts of VITRO-SKIN, the decontamination approaches, or insufficient statistical power for the study. While these variables must be taken into account in future studies, the artificial skin system we describe appears to show promise for the discovery of molecular mechanisms by which these pathogens persist and transfer in healthcare settings.

Pathogen transfer rates were significantly higher in low inoculum samples than in high. While it is unclear what factor or factors caused this difference, it is possible that higher loadings led to the formation of clumps of bacteria instead of individual cells or 
thin layers. This may have prevented much of the bacteria present on the coupon from contacting the secondary coupon, limiting the amount transferred. Future efforts will be required to characterize the deposition of different amounts of bacteria on the surface of VITRO-SKIN and to devise methods to achieve even distribution of bacteria across the surface in a way that recapitulates a human skin sample.

While this study investigated various decontamination methods relevant to pathogen transfer in healthcare settings, this study was not intended to serve as an evaluation of these methods or to provide recommendations on their effectiveness. Instead, a limited number of relevant decontamination methods were included to show the value of this model in future studies and to grapple with the influence of the inclusion of a background flora on transfer and decontamination rates. The limitations imposed by our simulated handwashing method were apparent. By not duplicating the force of water pressure on the artificial skin surface, a significant amount of pathogen transmission still occurred in the "washed" samples; generally, only a $30-60 \%$ reduction in transmission when compared to the unwashed controls. Hand washing procedures specified by the CDC instruct individuals to wash their hands with running water, where the force of the water has been shown to reduce bacterial loads. Without the force of running water in our scenario, more bacteria can remain on the hands even with the friction applied while rubbing and soaking in water afterwards $[14,25,26]$. Additionally, as described in the Materials and Methods, the VITRO-SKIN was not dried completely after the simulated-hand washing. This may have aided in bacterial transfer, similar to how residual moisture on hands has the potential to transfer bacterial loads more than dried hands $[25,26]$. The low contact time associated with the application of antimicrobial soap may have also played a role in the relative low success of hand washing observed in this study. Ultimately, uncovering challenges with the decontamination methods utilized in this study highlights the utility of the VITRO-SKIN system for the evaluation of factors relating to the effectiveness of handwashing and decontamination in future studies.

\section{Conclusions}

Here, we describe the development of an in vitro method that utilizes a synthetic skin surrogate in addition to a defined, customizable microbial community mimicking the human skin flora. This approach allows various pathogen transmission pathways to be quantified, including skin-to-skin and skin-to fomite-to skin contact scenarios, in a manner that does not involve human subject testing. Our results illustrate the value of simulating a holistic microbial community for transfer studies by elucidating differences in different pathogen transmission rates and resistance to common decontamination practices. Indeed, multiple differences in transmission rates between individual $\mathrm{ESKAPE}+\mathrm{C}$ pathogens were identified suggesting areas for future research focus. Ultimately, we believe this method will contribute to improvements in pathogen transmission modeling in healthcare settings. Future work should be performed to establish the concordance between pathogen transfer on hands and synthetic matrices, and to verify that the relative transmissibility of individual pathogens described herein is extensible to the clinical environment.

\section{Methods}

Bacterial culturing

Microorganisms used for this effort were sourced from ATCC or the CDC \& FDA Antibiotic Resistance Isolate Bank (Table 1) [11].

All microorganisms were propagated according to CDC and ATCC guidelines (Table 2). An Environmental Protection Agency (EPA) Standard Operating Procedure (SOP) was used as a guideline for the preparation of $C$. difficile endospores [27]. Greater than $90 \%$ of the bacterial preparation were spores. All media and media supplements were acquired from Teknova and anaerobic equipment from $\mathrm{BD}$.

\section{Determination of bacterial count}

To facilitate rapid viability screening using culture methods, three separate mixtures were created for testing (Table 3). The viability of each ESKAPE $+\mathrm{C}$ pathogen was assessed on three selective medias: mannitol salt agar (MSA), eosin methylene blue (EMB) agar, and $C$. difficile agar, with the indicated antibiotics included (Acros Organics for gentamicin and Alfa Aesar for ampicillin) (See Table 3). Plates were supplemented with antibiotics and allowed to dry overnight prior to testing. Bacteria were enumerated by serial dilution in PBS (Teknova) and subsequent plate count following incubation for $72-96 \mathrm{~h}$ at $36^{\circ} \mathrm{C}$. C. difficile growth occurred under anaerobic conditions.

Preparation of synthetic skin and indirect testing surfaces VITRO-SKIN N-19 (IMS Inc.) was used to simulate both skin-to-skin (i.e., direct) and skin-to fomite-to skin (i.e., indirect) transmission. All VITRO-SKIN sheets were cut into $3 \times 3 \mathrm{~cm}$ coupons prior to hydration. VITRO-SKIN was used within $24 \mathrm{~h}$ of hydration. Stainless steel coupons $(3 \times 3 \mathrm{~cm})$ (Home Depot) were cleaned with $70 \%$ isopropyl alcohol, rinsed with deionized (DI) water, and allowed to dry. After drying, surfaces were steam sterilized by autoclaving prior to testing. Nitrile gloves (VWR) and cotton 
Table 2 Bacterial growth conditions

\begin{tabular}{|c|c|c|}
\hline Microorganism & Growth Media & Growth Conditions \\
\hline B. linens ATCC 9172 & Tryptic Soy Broth & Aerobic, $30^{\circ} \mathrm{C}$ \\
\hline C. matruchotii ATCC 14265 & Brain Heart Infusion Broth with $2 \%$ yeast extract & Aerobic, $36^{\circ} \mathrm{C}$ \\
\hline P. acnes ATCC 11827 & Tryptic Soy Broth with 5\% Sheep's Blood & Anaerobic, $36^{\circ} \mathrm{C}$ \\
\hline E. coli ATCC 9637 & Tryptic Soy Broth & Aerobic, $36^{\circ} \mathrm{C}$ \\
\hline L. gasseri ATCC 33323 & Lactobacilli MRS Broth & Aerobic, $36^{\circ} \mathrm{C}$ \\
\hline M. luteus ATCC 4698 & Tryptic Soy Broth & Aerobic, $30^{\circ} \mathrm{C}$ \\
\hline S. epidermidis ATCC 12228 & Tryptic Soy Broth & Aerobic, $36^{\circ} \mathrm{C}$ \\
\hline S. pyogenes ATCC 19615 & Tryptic Soy Broth with 5\% Sheep's Blood & $5 \% \mathrm{CO}_{2}, 36^{\circ} \mathrm{C}$ \\
\hline A. baummannii AR Bank 275 & Tryptic Soy Broth & Aerobic, $36^{\circ} \mathrm{C}$ \\
\hline E. faecium AR Bank 579 & Tryptic Soy Broth & Aerobic, $36^{\circ} \mathrm{C}$ \\
\hline K. pneumoniae AR Bank 139 & Tryptic Soy Broth & Aerobic, $36^{\circ} \mathrm{C}$ \\
\hline E. aerogenes AR Bank 161 & Tryptic Soy Broth & Aerobic, $36^{\circ} \mathrm{C}$ \\
\hline S. aureus AR Bank 219 & Tryptic Soy Broth & Aerobic, $36^{\circ} \mathrm{C}$ \\
\hline C. difficile (endospores) ATCC 43598 & Endospore Preparation & Anerobic, $36^{\circ} \mathrm{C}$ \\
\hline E. cloacae AR Bank 365 & Tryptic Soy Broth & Aerobic, $36^{\circ} \mathrm{C}$ \\
\hline P. aeruginosa AR Bank 230 & Tryptic Soy Broth & Aerobic, $36^{\circ} \mathrm{C}$ \\
\hline
\end{tabular}

surfaces were cut to $3 \times 3 \mathrm{~cm}$, placed in a sterile container exposed to UV light for approximately $1 \mathrm{~h}$. Sterilized surfaces were used within $24 \mathrm{~h}$. Cotton surfaces were cut from a new laboratory cotton/polyester blend coat. Negative controls (VITRO-SKIN coupons not inoculated with bacteria) were included to confirm that no ESKAPE $+\mathrm{C}$ pathogens were present on sterilized fomite surfaces.

\section{Preparation of VITRO-SKIN with bacterial inoculum}

At the time of testing, pathogenic and background cultures were pelleted by centrifuging at $5000 \mathrm{x} \mathrm{g}$ for $10 \mathrm{~min}$ (excluding anaerobic microorganisms or cultures prepared in sheep's blood) and resuspended in $2 \mathrm{~mL}$ of PBS. Resuspended bacteria were combined per the appropriate mix (Table 3) at the appropriate spike-in level and brought up to $5 \mathrm{~mL}$ using PBS. Spike in target levels were $\sim 10^{6} \mathrm{CFU}$ per VITRO-SKIN for "high" $\sim 10^{2}$ CFU for "low." Actual spike in values were measured and reported (Fig. 2). On the day of testing, one mix containing pathogens plus background and one mix containing only background microorganisms was prepared. Once the appropriate pathogen and background mixes were prepared, $0.100 \mathrm{~mL}$ of a bacterial mix was added per hydrated VITRO-SKIN coupons and spread evenly using a sterile spreader, avoiding edges. The inoculated coupons were dried at $36^{\circ} \mathrm{C}$ for 45 min or until visibly dried.

\section{Simulation of direct contact scenario}

For the no-wash direct contact scenario, a primary VITRO-SKIN coupon containing a pathogen mix was touched to a secondary VITRO-SKIN coupon containing

Table 3 Bacterial mixtures for testing

\begin{tabular}{lll}
\hline Mixture & Selective Agar & Bacteria \\
\hline 1 & MSA and EMB with $16 \mu \mathrm{g} / \mathrm{mL}$ of Ampicillin & Background (See Table 1) \\
A. baumannii & E. faecium \\
& & K. pneumoniae \\
& & Background (See Table 1) \\
& MSA with $24 \mu \mathrm{g} / \mathrm{mL} \mathrm{Gentamicin}$ & E. aerogenes \\
& EMB with $8 \mu \mathrm{gL}$ of Gentamicin & S. aureus \\
& BSA and EMB with $8 \mu \mathrm{g} / \mathrm{mL}$ of Gentamicin & Background (See Table 1) \\
& C. difficile Agar & C. difficile endospores \\
& E. cloacae & P. aeruginosa
\end{tabular}


only background microbiota by evenly applying pressure for $10 \mathrm{~s}$ using sterile forceps. The secondary VITROSKIN coupon was then added to $10 \mathrm{~mL}$ PBS and vortexed for $3 \mathrm{~min}$ to release the bacteria. Recovered bacteria was then appropriately diluted and plated on selective media. For simulated hand washing, a procedure was adapted from Arinder et al. [12] To a pathogeninoculated VITRO-SKIN coupon, $0.100 \mathrm{~mL}$ of hospitalgrade hand soap (Thermo Scientific SoftCide Hand Soap) was applied to the bacterial-laden surface. A second pathogen-inoculated VITRO-SKIN coupon was pressed evenly onto the first, allowing the soap to spread evenly between both coupons. The coupons were rubbed against each other 20 times to achieve the same amount of foam as normal hand washing. After washing, the secondary VITRO-SKIN was rinsed sequentially using two separate $10 \mathrm{~mL}$ conical tubes containing sterile PBS. Following the second rinse, the coupon was rinsed in $10 \mathrm{~mL}$ of Dey-Engley (D/E) broth. After the D/E broth rinse, the washed VITRO-SKIN was touched to a new VITROSKIN coupon that contained only background microbes by evenly applying pressure for $10 \mathrm{~s}$ using sterile forceps. The new VITRO-SKIN with the transferred bacteria was added to $10 \mathrm{~mL}$ of PBS, vortexed for three minutes, and appropriately diluted and plated on selective media.

\section{Simulation of indirect contact scenario}

Indirect contact events were performed in a similar manner as direct contact events (Fig. 1b). Dried and inoculated VITRO-SKIN samples were prepared and touched to one of the three different surface types (i.e., nitrile gloves, cotton cloth to represent a patient bedsheet, and stainless steel to represent medical equipment). This testing occurred with and without a decontamination step on the surface following the initial transfer across two pathogen spike-in levels. The cleaning procedure for stainless steel and gloves was performed with a fresh, broad spectrum hospital disinfectant wipe per manufacturer instructions (Metrex Caviwipes Bleach ${ }^{\circ}$ ). The cloth surfaces were cleaned with a simulated hot-water cleaning to replicate how textiles are cleaned in a hospital washing machine. Afterward, a secondary coupon containing only the background microbiome was touched to the cleaned or noncleaned surface. The simulated hot water cloth cleaning procedure was adapted from "A Sanitary Study of Commercial Laundry Practices," recommended by the CDC [28]. All replicates of soiled cotton coupons were placed in a sterile beaker with a sterile stir bar containing $200 \mathrm{~mL}$ of sterile water to ensure all cloth replicates were submerged and were rinsed for $5 \mathrm{~min}$ at $43^{\circ} \mathrm{C}$. After first rinse, the water was dispensed into a waste container to be autoclaved. Sterile water $(200 \mathrm{~mL} ; 0.027 \mu \mathrm{L} / \mathrm{mL}$ stock detergent (All ${ }^{\circ}$ Free \& Clear) was added to a new, sterile beaker to ensure all cotton replicates were submerged and allowed to stir to provide agitation for $10 \mathrm{~min}$ at $52{ }^{\circ} \mathrm{C}$. Afterward, $2 \%$ bleach was added to the mixture and was allowed to stir to provide agitation for $15 \mathrm{~min}$ at $78^{\circ} \mathrm{C}$. The water was then removed and placed in a waste container for autoclaving. Sterile water $(200 \mathrm{~mL})$ was added to a new, sterile beaker to ensure all cotton replicates were submerged and was allowed to stir for $3 \mathrm{~min}$ at $78^{\circ} \mathrm{C}$. The water was removed appropriately and placed in a waste container for autoclaving. The wash step for $3 \mathrm{~min}$ at $78^{\circ} \mathrm{C}$ was repeated twice. After the final rinse, each cotton replicate was placed in an appropriate sterile container and placed in an oven at $70^{\circ} \mathrm{C}$ for 30 min or until visibly dried. Once dried, each replicate was added to $10 \mathrm{~mL}$ PBS, vortexed for $3 \mathrm{~min}$, and enumerated per standard spread plating technique.

\section{Culture analysis}

For each pathogen mixture and simulated contact scenario, the following controls were harvested and plated: one primary inoculated VITRO-SKIN as the pre-transfer control; one clean VITRO-SKIN (i.e., no background skin microbiome or ESKAPE $+\mathrm{C}$ pathogens) as the negative control; one clean or sterile surface (i.e. fomite) per surface type as a negative control. One sterile agar plate per agar type was incubated alongside test plates to ensure plate sterility. Each pathogenic microorganism per mixture type per testing simulation was struck for isolation to ensure there was no contamination. A volume of $0.100 \mathrm{~mL}$ of each dilution buffer, harvesting buffer, etc. was plated onto sterile TSA to ensure no contamination of each respective buffer at the time of testing.

Following the transmission event simulations, each replicate was aseptically placed into separate conicals containing $10 \mathrm{~mL}$ of PBS and vortexed at max speed for at least $3 \mathrm{~min}$. Afterward, individual $1 \mathrm{~mL}$ aliquots $(n=$ 2) were plated directly onto the appropriate selective media and incubated at the appropriate temperatures. Colonies were counted manually to quantify the number of CFUs.

\section{Viability and experimental calculations}

Equations 1 and 2 below were used for culturedependent method analysis. Equation 1 was used to determine the number of viable bacteria of a given strain on the surface of a VITRO-SKIN carrier following elution in $10 \mathrm{~mL}$ of buffer. Eq. 2 was used to generate the average CFU per carrier across multiple experimental replicates.

$$
\begin{aligned}
\text { CFU per Carrier }= & {[(\text { Dilution Plate\# } 1+\text { Dilut }(\text { du }) \text { Plate\#2 }) / 2] } \\
& x \text { DF } x \text { Elution Volume }
\end{aligned}
$$

Equation $1 \mathrm{CFU}$ per Carrier 


\section{Equation 2 Average CFU per Carrier}

\section{Statistical analysis}

Statistical analysis of Log difference between the control VITRO-SKIN and the resulting VITRO-SKIN from transfer of the eight ESCKAPE+C pathogens were performed by ANOVA using multiple factors as described. The analysis was performed using the 'aov' function in ' $R$ ' statistical package through 'Rstudio' [29]. The ANOVA was followed by a Tukey Honest Significant Difference Test utilizing the 'TukeyHSD' function. The detection limit for CFU counts were used for values below that limit.

\section{Supplementary information}

Supplementary information accompanies this paper at https://doi.org/10. 1186/s12879-020-05121-4.

\section{Additional file 1.}

\section{Abbreviations}

HAl: Healthcare-acquired infections; ESKAPE: Enterococcus faecium Staphylococcus aureus, Klebsiella pneumoniae, Acinetobacter baumannii, Pseudomonas aeruginosa, and Enterobacter species; ESKAPE+C: Enterococcus faecium, Staphylococcus aureus, Klebsiella pneumoniae, Acinetobacter baumannii, Pseudomonas aeruginosa, Enterobacter species and Clostridioides difficile; CDC: Centers for disease control and prevention; FDA: Food and drug administration; AR: Antibiotic resistance; CFU: Colony forming units; ANOVA: Analysis of variance; PBS: Phosphate buffered saline;

EPA: Environmental protection agency; SOP: Standard operating procedure; MSA: Mannitol salt agar; EMB: Eosin methylene blue; D/E: Dey-Engley; DI: Deionized

\section{Acknowledgements}

The authors would like to thank Jim Gibson for his help creating the contact scenario figure.

\section{Authors' contributions}

All authors have read and approved the manuscript. Conceptualization: KLW, NW, KLT, FCH. Data curation: KLW, DSL, ADK, KQS, NCA, KLT, FCH. Laboratory analysis: KLW, DSL, KQS, NW. Funding acquisition: KLW, NW, KLT, FCH. Data analysis: KLW, DSL, ADK, NCA, GDG, VP, CAA, KLT, FCH. Project administration: KLT, FCH. Writing - original draft: KLW, DSL, ADK, GDG, CAA, KLT, FCH. Writing - review \& editing: KLW, DSL, ADK, GDG, KLT, FCH.

\section{Funding}

This work was supported by the Centers for Disease Control and Prevention's investments to combat antibiotic resistance under award number 200-201875D30118 C02922 (https://cdc.gov).

\section{Availability of data and materials}

All data generated or analyzed during this study are included in this published article and its supplementary information files.

Ethics approval and consent to participate Not applicable.
Consent for publication

Not applicable.

\section{Competing interests}

The authors declare that they have no competing interests.

Received: 14 January 2020 Accepted: 27 May 2020

Published online: 12 June 2020

\section{References}

1. Burnham JP, Olsen MA, Kollef MH. Re-estimating annual deaths due to multidrug-resistant organism infections. Infect Control Hosp Epidemiol. 2019;40(1):112-3.

2. Otter JA, Yezli S, Salkeld JAG, French GL. Evidence that contaminated surfaces contribute to the transmission of hospital pathogens and an overview of strategies to address contaminated surfaces in hospital settings. Am J Infect Control. 2013;41(5):S6-11.

3. Guerrero DM, Nerandzic MM, Jury LA, Jinno S, Chang S, Donskey CJ. Acquisition of spores on gloved hands after contact with the skin of patients with Clostridium difficile infection and with environmental surfaces in their rooms. Am J Infect Control. 2012;40(6):556-8.

4. Weber DJ, Anderson DJ, Rutala WA. The role of the surface environment in healthcare-associated infections. Curr Opin Infect Dis. 2013;26(4):338-44.

5. Weber DJ, Rutala WA, Miller MB, Huslage K, Sickbert-Bennett E. Role of hospital surfaces in the transmission of emerging health care-associated pathogens: Norovirus, Clostridium difficile, and Acinetobacter species. Am J Infect Control. 2010;38(5):S25-33.

6. Boucher HW, Talbot GH, Bradley JS, Edwards JE, Gilbert D, Rice LB, et al. Bad bugs, no drugs: no ESKAPE! An update from the Infectious Diseases Society of America. Clin Infect Dis Off Publ Infect Dis Soc Am. 2009;48(1):1-12.

7. Santajit S, Indrawattana N. Mechanisms of antimicrobial resistance in ESKAPE pathogens. Biomed Res Int. 2016;2016:2475067.

8. Slimings C, Riley TV. Antibiotics and hospital-acquired Clostridium difficile infection: update of systematic review and meta-analysis. J Antimicrob Chemother. 2014;69(4):881-91.

9. Centers for Disease Control and Prevention. Antibiotic Resistance Threats in the United States 2013 [Internet]. 2013 [cited 2019 Aug 6]. Report No: Washington: CDC. Available from: https://www.cdc.gov/drugresistance/ threat-report-2013/pdf/ar-threats-2013-508.pdf.

10. Tacconelli E, Carrara E, Savoldi A, Harbarth S, Mendelson M, Monnet DL, et al. Discovery, research, and development of new antibiotics: the WHO priority list of antibiotic-resistant bacteria and tuberculosis. Lancet Infect Dis. 2018;18(3):318-27.

11. Lutgring JD, Machado M-J, Benahmed FH, Conville P, Shawar RM, Patel J, et al. FDA-CDC antimicrobial resistance isolate Bank: a publicly available resource to support research, development, and regulatory requirements. Kraft CS, editor. J Clin Microbiol. 20178;56(2):e01415-7.

12. Arinder $P$, Johannesson $P$, Karlsson I, Borch E. Transfer and decontamination of $S$. aureus in transmission routes regarding hands and contact surfaces. Nychas G-J, editor. Plos One. 2016;11(6):e0156390.

13. Dyer $C$, Hutt LP, Burky R, Joshi LT. Biocide resistance and transmission of Clostridium difficile spores spiked onto clinical surfaces from an American healthcare facility. Appl Environ Microbiol. 2019 Jul;12:e01090-19.

14. World Health Organization, editor. WHO guidelines on hand hygiene in health care. Geneva, Switzerland: WHO Press; 2009.

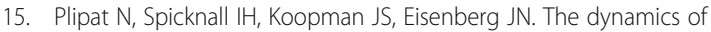
methicillin-resistant staphylococcus aureusexposure in a hospital model and the potential for environmental intervention. BMC Infect Dis. 2013 Dec 17; 13(1):595.

16. Williams C, Davis DL. Methicillin-resistant Staphylococcus aureus fomite survival. Clin Lab Sci J Am Soc Med Technol. 2009;22(1):34-8. 
17. Jefferies JMC, Cooper T, Yam T, Clarke SC. Pseudomonas aeruginosa outbreaks in the neonatal intensive care unit - a systematic review of risk factors and environmental sources. J Med Microbiol. 2012;61(Pt_8):1052-61.

18. Zapka CA, Campbell EJ, Maxwell SL, Gerba CP, Dolan MJ, Arbogast JW, et al. Bacterial hand contamination and transfer after use of contaminated bulksoap-refillable dispensers ${ }^{7}$. Appl Environ Microbiol. 2011;77(9):2898-904.

19. Pires dos Santos R, Jacoby T, Pires Machado D, Lisboa T, Gastal SL, Nagel FM, et al. Hand hygiene, and not ertapenem use, contributed to reduction of carbapenem-resistant Pseudomonas aeruginosa rates. Infect Control Hosp Epidemiol. 2011;32(6):584-90.

20. Klevens RM, Edwards JR, Richards CL, Horan TC, Gaynes RP, Pollock DA, et al. Estimating health care-associated infections and deaths in U.S. hospitals, 2002. Public Health Rep. 2007;122(2):160-6.

21. Nekkab N, Astagneau P, Temime L, Crépey P. Spread of hospital-acquired infections: A comparison of healthcare networks. Tanaka MM, editor. Plos Comput Biol. 2017;13(8):e1005666.

22. Pitol AK, Bischel HN, Boehm AB, Kohn T, Julian TR. Transfer of enteric viruses adenovirus and coxsackievirus and bacteriophage MS2 from liquid to human skin. Elkins CA, editor. Appl Environ Microbiol. 2018;84(22):e01809e01818, /aem/84/22/e01809-18.atom.

23. Reddy PN, Srirama K, Dirisala VR. An update on clinical burden, diagnostic tools, and therapeutic options of Staphylococcus aureus. Infect Dis Res Treat. 2017;10:117991611770399.

24. Clarke SR, Foster SJ. Surface Adhesins of Staphylococcus aureus. In: Advances in Microbial Physiology [Internet]: Elsevier; 2006. p. 187-224. [cited 2019 Sep 6] Available from: https://linkinghub.elsevier.com/retrieve/pii/S006529110651 0045 .

25. Todd ECD, Greig JD, Bartleson CA, Michaels BS. Outbreaks where food workers have been implicated in the spread of foodborne disease. Part 3. Factors contributing to outbreaks and description of outbreak categories. J Food Prot. 2007;70(9):2199-217.

26. Patrick DR, Findon G, Miller TE. Residual moisture determines the level of touch-contact-associated bacterial transfer following hand washing. Epidemiol Infect. 1997;119(3):319-25.

27. US Environmental Protection Agency, Office of Pesticide Programs. EPA MLB SOP MB-28: Procedure for the Production and Storage of Spores of Clostridium difficile for Use in the Efficacy Evaluation of Antimicrobial Agents [Internet]. 2017 [cited 2019 Sep 6]. Report No.: EPA-HQ-OPP-2016-0753. Available from: https://www.epa.gov/pesticide-analytical-methods/ antimicrobial-testing-methods-procedures-mb-28.

28. Arnold L. A sanitary study of commercial laundry practices. Am J Public Health Nations Health. 1938;28(7):839-44.

29. R Core Team. R: a language and environment for statistical computing [internet]. Vienna, Austria: R Foundation for Statistical Computing; 2019. Available from: https://www.R-project.org/.

\section{Publisher's Note}

Springer Nature remains neutral with regard to jurisdictional claims in published maps and institutional affiliations.

Ready to submit your research? Choose BMC and benefit from:

- fast, convenient online submission

- thorough peer review by experienced researchers in your field

- rapid publication on acceptance

- support for research data, including large and complex data types

- gold Open Access which fosters wider collaboration and increased citations

- maximum visibility for your research: over $100 \mathrm{M}$ website views per year

At $\mathrm{BMC}$, research is always in progress.

Learn more biomedcentral.com/submissions 